\title{
Determinação do índice de refração dos materiais pelo método de Ptolomeu
}

\author{
Determination of the refractive index of materials by the method of Ptolemy
}

\author{
Marcos Paulo Martinho*1, Vitorvani Soares ${ }^{2}$
}

${ }^{1}$ Instituto Federal de Educação, Ciência e Tecnologia do Rio de Janeiro, Av Maria Luzia, Rio de Janeiro, RJ, Brasil

${ }^{2}$ Instituto de Física, Universidade Federal do Rio de Janeiro, Cidade Universitária, Rio de Janeiro, RJ, Brasil

Recebido em 25 de Novembro de 2016. Revisado em 13 de Fevereiro de 2017. Aceito em 14 de Fevereiro de 2017

\begin{abstract}
É conhecido que objetos observados através de materiais transparentes têm suas imagens deslocadas de sua posição original. A experiência da moeda oculta no fundo do recipiente e que se torna visível com a colocação de certa quantidade de água dentro dele é um exemplo comum. O que poucos sabem é que este procedimento já teria sido descrito por Ptolomeu, no século II, ao apresentar o seu método de análise do fenômeno de refração em seu livro de Óptica, um dos livros mais antigos na história da física. Apresentamos neste trabalho o método de Ptolomeu e discutimos uma variação quantitativa do seu procedimento: determinamos o grau de encurvamento que um dióptro produz na localização da imagem de um objeto e estabelecemos a relação matemática entre a sua posição angular real e o ângulo de encurvamento correspondente.

Palavras-chave: refração, experimento, método científico, Ptolomeu.
\end{abstract}

It is known that objects observed through transparent materials have their images shifted from their original position. The experience of the coin hidden in the bottom of the container and which becomes visible with the placement of a certain amount of water inside it is a common example. What few people know is that this procedure would have been described by Ptolemy in the second century when he presented his method of analyzing the phenomenon of refraction in his book of Optics, one of the oldest books in the history of physics. We present in this work the Ptolemy's method and discuss a quantitative variation of its procedure: we determine the degree of curvature that the boundary between two transparent materials produces in the image location of an object and we establish the mathematical relationship between its real angular position and the corresponding angle of curvature.

Keywords: Refraction, experiment, scientific method, Ptolemy.

\section{Introdução}

O estudo da refração é um assunto de grande importância para a ciência e é tema presente em todos os compêndios de física básica. Muitas explicações de fenômenos ópticos derivam dele, tais como o estudo das lentes, fibra óptica, arco-íris, etc. Aprendemos também nos livros didáticos que as regras que balizam este fenômeno foram enunciadas no século XVII por Snell-Descartes, cerca de 2000 anos após Euclides enunciar a lei da reflexão. Este intervalo de tempo é muito grande entre duas leis que são

*Endereço de correspondência: marcos.martinho@ifrj.edu.br apresentadas uma em seguida à outra nos livros escolares.

Feynman, em seu livro The Feynman Lectures on Physics [1], ressalta que o estabelecimento da relação matemática entre a posição angular do objeto e o ângulo de encurvamento da sua imagem foi um grande quebra-cabeças para a ciência da Antiguidade. De fato, este assunto é comentado em obras clássicas deste período histórico [2]. Entretanto, nenhum estudo sistemático sobre este tema é apontado pelos historiadores da ciência até o século II d.C., quando o astrônomo Cláudio Ptolomeu, em seu livro de óptica, publica o primeiro estudo quantitativo conhecido acerca do fenômeno da refração. 
A obra contendo a Óptica de Ptolomeu é composta de cinco livros que ficaram perdidos durante séculos até que uma versão árabe fosse encontrada pelo Almirante Eugênio da Sicília, no século XII. Este texto em árabe foi traduzido para o latim nesta mesma época pelo próprio descobridor. Somente séculos mais tarde, em 1885, foi produzida uma edição latina com comentários em italiano [3]; uma outra edição, ainda em latim mas com comentários em francês, foi impressa cerca de 70 anos depois, em 1956 [4]. Uma tradução do latim para o inglês, somente do Livro V, foi feita em 1958 [5] e, mais recentemente, em 1996, foi publicada uma tradução do latim para o inglês de todo o livro de Óptica [6]. Estes autores procuram destacar a habilidade de Ptolomeu em realizar, ainda no início da nossa era, uma série de experimentos para a determinação da lei da refração usando procedimentos científicos considerados modernos.

Como pode ser observado nas traduções, Ptolomeu estabelece uma hipótese (uma possível relação entre o ângulo da posição da imagem e o ângulo correspondente da posição do objeto), constrói um goniômetro, faz medidas angulares com intervalos de $10^{\circ}$ para três dioptros diferentes usando os meios ar, água e vidro e, finalmente, estabelece uma conclusão a partir dos dados obtidos. Em seu livro, Ptolomeu não somente organiza várias tabelas com os dados relativos às posições angulares do objeto e da sua imagem como também apresenta uma análise quantitativa dos seus resultados experimentais, a denominada lei de refração de Ptolomeu. As Figuras 6, 9 e 10 do presente trabalho, retiradas das referências [3] $[6]$, retratam a atualidade do procedimento adotado por Ptolomeu.

O livro de Feynman é um dos poucos livros contemporâneos que citam a lei da refração de Ptolomeu nominalmente [1] mas não faz uso dela em seu curso. Os cuidadosos experimentos realizados por Ptolomeu para determinar a lei de refração foram analisados por Wilk mais recentemente [7] e este autor também conclui que o procedimento ptolomaico é idêntico aos procedimentos efetuados nos laboratórios didáticos atuais. Animados por essa perspectiva, apresentamos neste artigo a reconstrução do experimento realizado por Ptolomeu para estudar a refração em seu tempo, utilizando sua metodologia. Nosso intuito é obter e analisar os dados a partir de seu ponto de vista: a determinação precisa da posição original de um objeto conhecendo-se a posição angular da sua imagem produzida pelos dioptros ar-acrílico e ar-água. Com este propósito, recriamos o experimento de Ptolomeu e realizamos a investigação da refração segundo sua orientações.

Ao consultar a literatura atual, observamos que a maior parte dos experimentos didáticos quantitativos sugeridos sobre refração estão ligados à óptica física $[8]$. Ao explorarmos este experimento realizado por Ptolomeu resgatamos uma genuína atividade oriunda das tradições da óptica geométrica, onde estabelecemos uma relação de causa e efeito entre as posições angulares do objeto e de sua imagem, através da observação direta destas grandezas físicas e sem o auxílio de lasers e instrumentos similares.

Assim como feito por Ptolomeu em seu livro e é mostrado em [3] , a atividade experimental discutida neste artigo está dividida em duas partes. Ptolomeu começa o capítulo dedicado à refração com a discussão do experimento da moeda que está no fundo do recipiente opaco e se torna visível após certa medida de água despejada em seu interior. Vamos substituir esta experiência por uma outra utilizando uma lente plano convexa. O objetivo deste experimento preliminar é similar ao que Ptolomeu quis demonstrar com o experimento da moeda: constatar que, diferente do espelho, um objeto visto através de um meio transparente tem a posição da sua imagem deslocada em relação à sua posição original. Em seguida determinamos o grau de desvio das posições angulares da imagem com o auxílio de um goniômetro. Em seu trabalho original, Ptolomeu estabelece somente uma relação geométrica de proporcionalidade entre as diferenças entre os ângulos observados. Em nosso trabalho obtemos os resultados experimentais, os analisamos e estabelecemos uma equação algébrica entre os ângulos relativos à posição do objeto e da sua imagem. Em seguida determinamos também os índices de refração dos meios dióptricos estudados no experimento.

\section{Aparato experimental}

Para o desenvolvimento desta prática experimental fazemos uso dos itens informados a seguir e mostrados nas Figuras 11 e 2. A descrição geométrica da posição da imagem de um objeto quando ele é observado através de um meio transparente pode ser compreendida inicialmente com a ajuda de cinco cilindros feito de acrílico que possuem um diâmetro $d=2.00(5) \mathrm{cm}$ e uma altura $h=2.00(5) \mathrm{cm}$ e cinco 


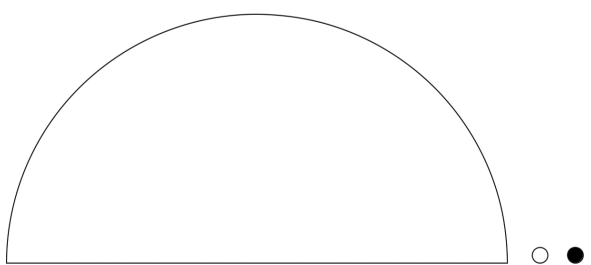

(a)

(b)

Figura 1: Material para a primeira atividade. (a) Vista superior e (b) vista de frente do disco semicilíndrico feito em acrílico, de diâmetro $D=56.00(5) \mathrm{cm}$ e uma altura $h=2.00(5) \mathrm{cm}$ igual à altura do pequeno cilindro de diâmetro $d=2.00(5) \mathrm{cm}$ e do pequeno disco preto também de mesmo diâmetro que o cilindro. Um esquadro e uma régua milimetrada também devem ser incluídos no material.

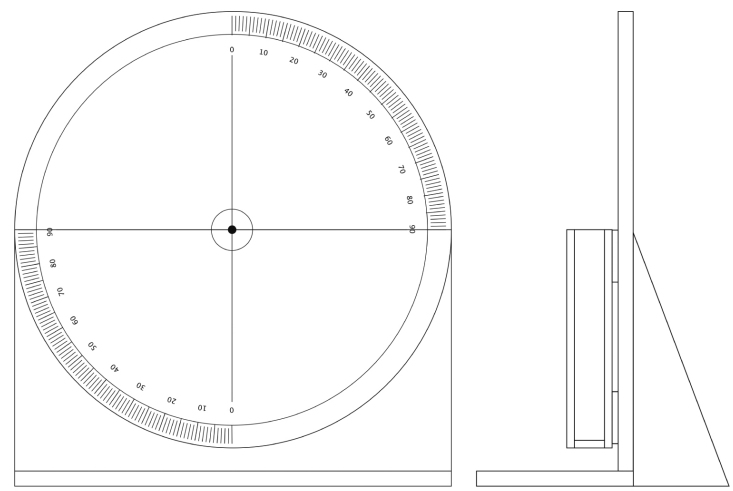

(a)

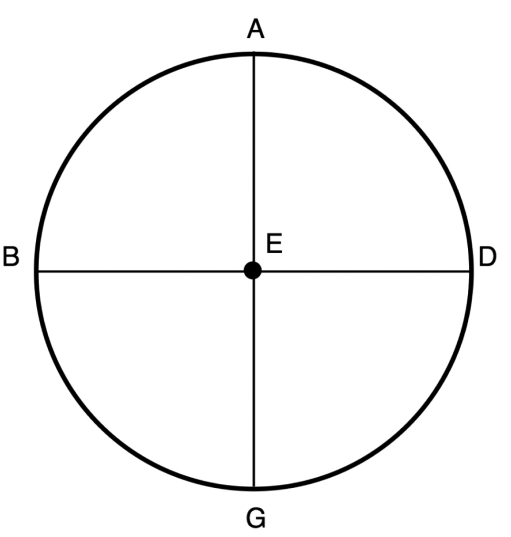

(b)

Figura 2: (a) Vista de frente e lateral do nosso baptistir. (b) Representação esquemática do baptistir.

pequenos discos não transparentes, de diâmetro igual ao diâmetro dos cilindros. Também temos à nossa disposição um disco semicilíndrico feito também em acrílico e que possui um diâmetro $D=56.00(5) \mathrm{cm}$ e uma altura $h=2.00(5) \mathrm{cm}$ igual à altura dos pequenos cilindros, como ilustrado na Figura 1 .

O segundo item é o baptistir, um instrumento por nós reproduzido conforme as orientações de Ptolomeu descritas no quinto livro da sua Óptica $\mid 36$. Trata-se de um recipiente semicilíndrico com um disco conectado a ele que serve como goniômetro. O disco tem um raio igual ao raio do semicilindro e tanto o disco quanto o recipiente foram reproduzidos em acrílico. As dimensões internas do recipiente semicilindrico são, em cm, 60.00(5) ×2.00(5) ×30.00(5) e o disco tem as seguintes dimensões: $60.00(5) \times$ $60.00(5) \times 1.00(5)$, como ilustrado na Figura 2(a). Sobre o disco desenhamos uma circunferência $A B G D$ com o centro em $E$ coincidente com o centro do disco e também estão representados dois diâmetros $A E G$ e $B E D$ perpendiculares entre si e passando pelo centro da circunferência $E$, como ilustrado esquematicamente na Figura 2(b). Dividimos cada quadrante da circunferência em noventa partes iguais, denominadas grau, e localizamos o centro da circunferência com um indicador colorido. Na seção 4 vamos empregar o baptistir para medir os ângulos da localização do objeto e da sua imagem correspondente e analisar quantitativamente a refração produzida por nossos dioptros (ar-acrílico e ar-água).

\section{Procedimento experimental}

A experiência da moeda oculta no fundo do recipiente e que se torna visível com a colocação de certa quantidade de água dentro dele, já teria sido descrita por Ptolomeu, o experimento que segue tem objetivo de mostrar quantitativamente o grau de encurvamento que uma lente de acrílico possui. Então dado uma lente plano-convexa, observada a imagem de um objeto a partir da face plana e objetos colocados ao longo da face curva, quais seriam as reais posições do objeto observado? Qual seria a relação matemática entre as posições reais e os ângulos de encurvamento?

A lente plano-convexa deverá ser colocada na horizontal e a observação deverá ser feita a partir da face plana frontal. Com uma régua localiza-se o centro da da lente $E$ que indica o centro da interface do segmento TL, de nosso sistema ar-acrílico. Para indicar esse ponto colocamos um cilindro de acrílico como indicado na Figura 3. Em seguida colocamos um objeto na posição y ao longo do semi-círculo. Devemos observar a imagem deste objeto através 


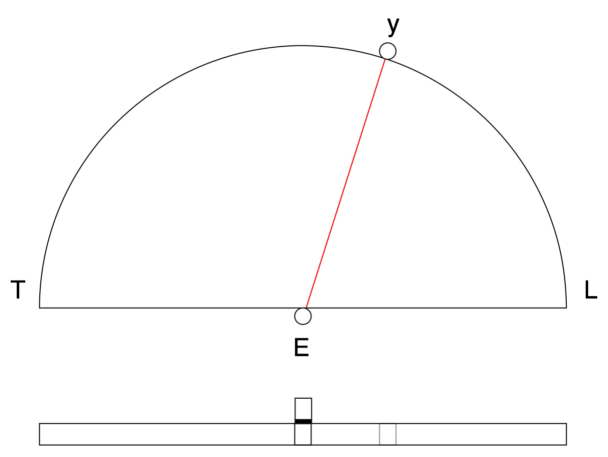

Figura 3: Vista superior e de frente da representação do material da primeira atividade: o semidisco em acrílico que representa o dioptro ar-acrílico, os pequenos cilindros, também em acrílico, e os pequenos discos que servem como objeto e guia de localização, respectivamente. (a) Localização do ponto de referência $E$ no ponto médio da face reta do semidisco.

do cilindro da posição $E$. A partir da visualização dessa imagem coloca-se outro cilindro sobre a lente e faz suas geratrizes coincidirem com as da imagem observada (Figura 4).

Ao realizar esta experiência, duas observações são imediatas. O ângulo da orientação não é o mesmo da imagem observada em relação à perpendicular à face reta $(E K)$ do semi disco, e a segunda observação é que a posição $H$ está sob à mesma perpendicular à ao segmento $T L$ do semidisco que origina na posição real $y$, conforme ilustrado na Figura 4.

Em seguida, distribuímos aleatoriamente outros cilindros similares ao longo da face curva e localizamos geometricamente as respectivas imagens desses objetos vistas pelo mesmo observador através do mesmo disco semicilíndrico transparente, como ilustrado na Figura 5. Desta figura podemos observar que: (1) todas as posições das imagens dos seus respectivos objetos apresentam uma posição angular

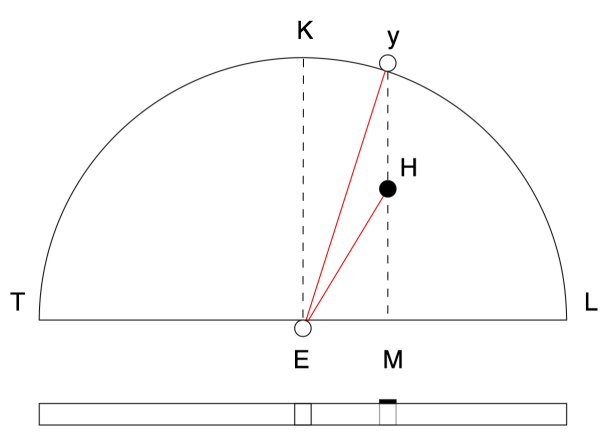

Figura 4: Alinhamento entre as posições do objeto e da imagem sobre o segmento de reta $y M$, perpendicular à face reta do semidisco.

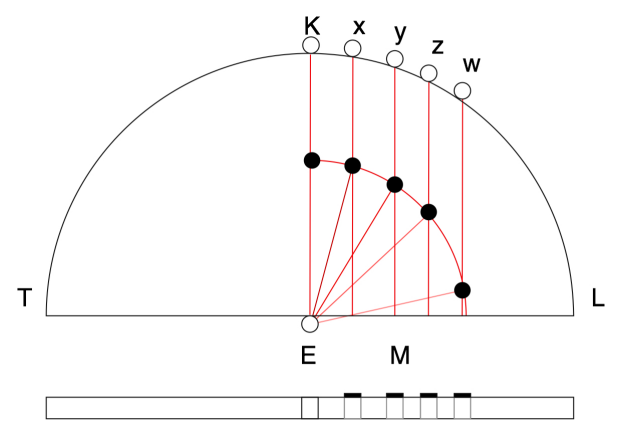

Figura 5: Vista superior e de frente da representação do material da primeira atividade: o semidisco de acrílico que representa o dioptro ar-acrílico, os pequenos cilindros e os pequenos discos pretos que servem como objeto e guia de localização. A ilustração também mostra que as posições das imagens dos cilindros repousam sobre um arco de curva.

em relação a normal à interface ar-acrílico maior do que a posição angular do objeto ao ser observado com o observador no meio menos denso. Dizemos então que o dioptro ar-acrílico apresenta a propriedade de refração: o encurvamento do raio visual definidos pela diretriz de observação; (2) todas as posições das imagens dos seus respectivos objetos se localizam sobre uma reta perpendicular à interface ar-acrílico que vai da posição original do objeto até esta interface $(T L) ;(3)$ todas as posições das imagens dos seus respectivos objetos se localizam sobre um arco de curva particular; (4) existe uma posição particular, $K$, definida pelo segmento de reta perpendicular à interface $(T L)$ que passa pelo seu ponto médio $E$ onde a imagem do objeto não sofre nenhum desvio; e (5) existe uma posição limite, $w$, para a observação da imagem objeto. Quando ele for colocado além desse limite, não haverá condições de observação da imagem correspondente.

A partir dessas observações podemos formular a seguinte questão: Conhecida a posição angular da imagem de um objeto, podemos determinar a sua posição real? A partir de uma primeira análise da Figura 4, poderíamos conjecturar uma solução trigonométrica, contudo vamos evitá-la para se aproximar da visão de Ptolomeu sobre o problema, já que a trigonometria só seria plenamente desenvolvida da forma que a concebemos somente na Índia, séculos mais tarde [9]. Na seção seguinte vamos empregar o baptistir para medir os ângulos da localização do objeto e da sua imagem correspondente e analisar quantitativamente a refração produzida por nosso dioptro ar-acrílico. 


\section{A refração para o dioptro ar-acrílico}

Estamos interessados em investigar quantitativamente as observações feitas na atividade anterior, onde observamos que os ângulos de orientação da imagem e do objeto não são iguais e que o primeiro é maior que o segundo quando o observador observa a imagem do objeto a partir do ar (meio menos denso) para o acrílico (meio mais denso).

Para observarmos os efeitos do semidisco transparente sobre a formação da imagem de um objeto, quando o objeto é observado através dele, procedemos conforme a metodologia empregada por Ptolomeu, do seguinte modo. Primeiramente, colocamos o baptistir na vertical. Em seguida, como indicado na Figura 6. colocamos um marcador no ponto $z$ do semidisco e o inserimos no recipiente. Medimos então o ângulo $K \hat{E} z$ ao longo do arco $G B$, em um dos quadrantes do recipiente semicilíndrico.

Finalmente, medimos o arco $A Z$ a partir do ponto $A$, em um dos quadrantes do disco $A B G D$, acima da interface recipiente-semidisco e oposto ao quadrante que contém o ângulo $K \hat{E} z$. Esta medida é realizada da seguinte forma: com o auxílio de um marcador colorido, localizamos a posição $Z$ nesse quadrante superior; com um dos olhos miramos na direção do marcador $E$ a partir de $Z$, de modo que eles estejam orientados com o ângulo de guia $A \hat{E} Z$ e, ao mesmo tempo, o marcador em $E$ oculte a imagem do marcador em $z$, conforme indicado na Figura 6

Seguindo a convenção de Ptolomeu, denominamos os ângulos $A \hat{E} Z$ e $K \hat{E} z$ de posição angular da imagem, $\theta_{2}$, e posição angular do objeto, $\theta_{1}$, res-

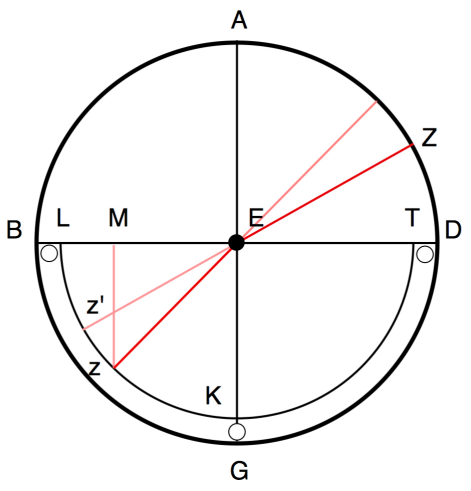

Figura 6: Baptistir e o dioptro ar-acrílico. Os pequenos círculos brancos representam os pequenos cilindros usados anteriormente e que agora servem apenas para impedir que o semidisco caia no interior do recipiente e, ao mesmo tempo, também servem para alinhar as faces retas do semidisco e do recipiente. pectivamente. Um conjunto de medidas para estes ângulos é apresentado na Tabela 1 e está representado graficamente na Figura 7

É interessante perceber que se observarmos o objeto em $G$ a partir da perpendicular $A E$, a guia não sofre nenhum desvio: a imagem continua sobre a mesma linha reta $A E$. Em todas as outras posições, entretanto, uma vez que aumentamos o $\operatorname{arco} A Z$, a posição angular da imagem, $\theta_{2}$, o arco $K z$ correspondente, a posição angular do objeto, $\theta_{1}$, também aumenta. Entretanto, o encurvamento é progressivamente maior, como podemos observar na Tabela 1.

Observamos também que, ao variarmos a posição angular da imagem, a posição angular do objeto varia, mas não na mesma proporção. Quanto maior a posição angular da imagem, maior é a diferença entre a posição angular da imagem e do objeto. Isto nos sugere analisar o comportamento da razão entre

Tabela 1: Medidas em graus para posição angular do objeto $\left(\theta_{1}\right)$ vs. posição da imagem $\left(\theta_{2}\right)$, para o dioptro ar-acrílico.

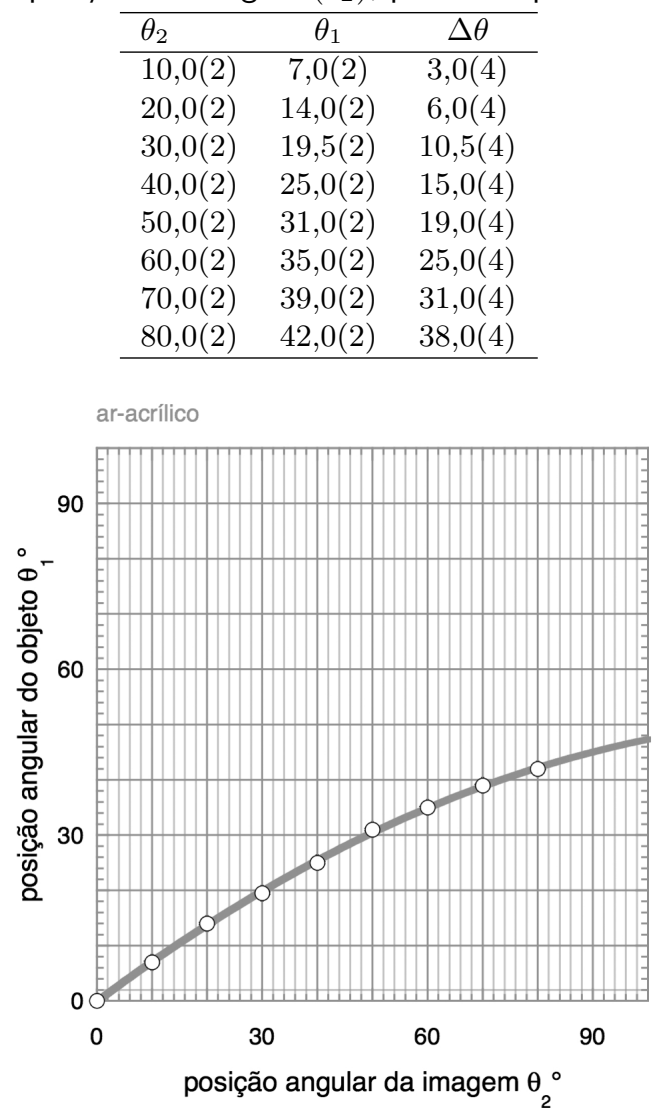

Figura 7: Medidas para a posição angular do objeto, $\theta_{1}$, vs. a posição angular da imagem, $\theta_{2}$, para o dioptro ar-acrílico e o objeto é observado a partir do meio menos denso (o ar) para o mais denso (o acrílico). 
essas duas grandezas, com representado no gráfico da Figura 7.

Percebemos da Figura 8 que, para as posições angulares consideradas, está razão varia linearmente com a posição angular da imagem do objeto, $\theta_{2}$. Desse modo, podemos escrever que

$$
\frac{\theta_{1}}{\theta_{2}}=a-b \theta_{2},
$$

onde $a$ e $b$ são constantes de valor aproximado

$$
a \approx 0,74(1)
$$

e

$$
b=\frac{0,74(1)-0,48(1)}{100(1)^{\circ}} \approx 0,0026(2) /^{\circ} .
$$

Estas constantes e suas incertezas são, respectivamente, o coeficiente linear e angular de (1), determinados por triangulação a partir do gráfico da Figura 8. Portanto, esta análise revela que a razão entre as medidas da posição angular da imagem e do objeto, $\theta_{1} / \theta_{2}$, varia linearmente com a posição angular da imagem do objeto, $\theta_{2}$, e podemos concluir que

$$
\theta_{1}=\theta_{2}\left(a-b \theta_{2}\right)
$$

ou, ainda, que

$$
\theta_{1}=a \theta_{2}\left(1-\frac{\theta_{2}}{\theta_{0}}\right)
$$

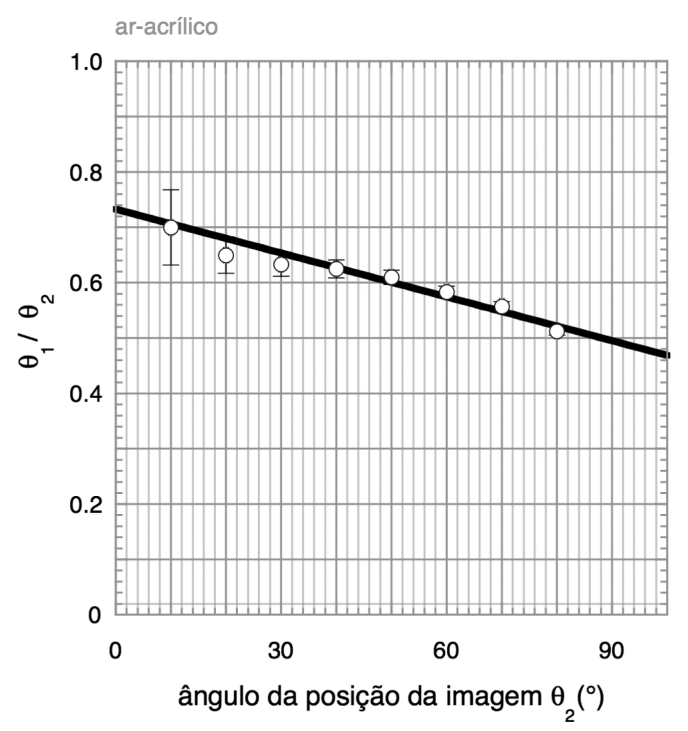

Figura 8: Razão entre as medidas da posição angular da imagem e do objeto, $\theta_{1} / \theta_{2}$ vs. posição angular da imagem do objeto, $\theta_{2}$, para o dioptro ar-acrílico e o objeto é observado a partir do meio menos denso (o ar) para o mais denso (o acrílico). onde

$$
\theta_{0}=\frac{a}{b}
$$

é uma constante que corresponde a um ângulo característico do experimento. Esta é a lei da refração estabelecida por Ptolomeu, no século II, a partir da análise dos seus experimentos com os dióptros arágua, ar-vidro e vidro-água. Assim, para o dioptro ar-acrílico, obtemos

$$
\theta_{0} \approx 280(30)^{\circ} \text {. }
$$

Conforme vimos, a Figura 7 representa o comportamento parabólico, definido pela equação (5), da relação entre a posição angular do objeto, $\theta_{1}$, e a posição angular da imagem do objeto, $\theta_{2}$. A partir da equação (5), também observamos que a posição angular da imagem do objeto, $\theta_{2}=90^{\circ}$, define um ângulo limite $\theta_{c}$ para a localização angular do objeto:

$$
\theta_{1}=a \theta_{2}\left(1-\frac{90^{\circ}}{\theta_{0}}\right)=45(3)^{\circ} .
$$

Este último resultado pode ser verificado imediatamente pelo experimentador. Para o nosso dioptro ar-acrílico temos que o valor experimental de $\theta_{c}$ é igual a $44(1)^{\circ}$. Portanto, a previsão da posição limite do objeto, pela lei de Ptolomeu, apresenta uma discrepância de $1^{\circ}$ em relação a posição angular real.

Observamos ainda que, para pequenas posições angulares das imagens, podemos reescrever a equação (5) na forma

$$
\theta_{1} \approx a \theta_{2}
$$

É importante salientar que na experimentação que realizamos o objeto é observado a partir do meio menos denso (o ar) para o mais denso (o acrílico). É natural, portanto, se perguntar o que ocorre quando observamos a formação da imagem do objeto a partir de um meio mais denso em direção a um meio menos denso. Para realizar tal experimento, rearranjamos o baptistir como ilustrado na Figura 9.

Um conjunto de medidas das posições angulares das imagens do objeto para diferentes posições angulares do objeto é apresentado na Tabela 2.

Observamos a partir da Tabela 2 que, para valores angulares à posição do objeto quando o objeto é observado a partir do meio menos denso (o ar) para o mais denso (o acrílico) são simétricos àqueles determinados quando o objeto observado a partir do meio mais denso (o acrílico) para o menos denso 


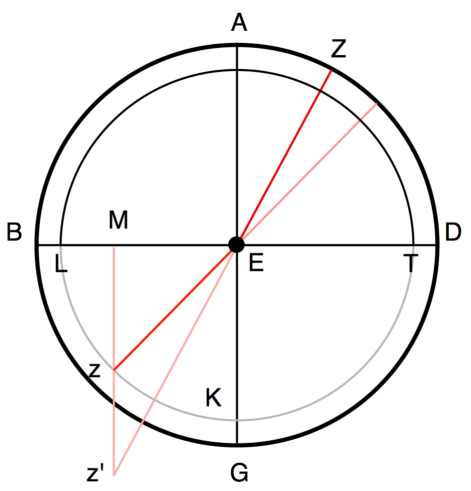

Figura 9: Baptistir e o dioptro ar-acrílico, onde o objeto em $z$, no meio menos denso (o ar), é agora observado a partir de $Z$, o meio mais denso (o acrílico). O semidisco de acrílico agora esta apoiado no recipiente semicircular $B G D$ do baptistir.

Tabela 2: Medidas em graus para posição angular da imagem $\left(\theta_{2}\right)$ e do objeto $\left(\theta_{1}\right)$ para o dioptro acrílico-ar.

\begin{tabular}{lcc}
\hline$\theta_{1}$ & $\theta_{2}$ & $\Delta \theta$ \\
\hline $10,0(2)$ & $6,5(2)$ & $3,5(4)$ \\
$20,0(2)$ & $13,0(2)$ & $7,0(4)$ \\
$30,0(2)$ & $19,5(2)$ & $10,5(4)$ \\
$40,0(2)$ & $25,5(2)$ & $14,5(4)$ \\
$50,0(2)$ & $31,5(2)$ & $18,5(4)$ \\
$60,0(2)$ & $36,0(2)$ & $24,0(4)$ \\
$70,0(2)$ & $39,0(2)$ & $31,0(4)$ \\
$80,0(2)$ & $42,5(2)$ & $37,5(4)$ \\
\hline
\end{tabular}

(o ar). Uma vez mais podemos analisar o comportamento da razão entre essas duas grandezas, com representado na equação (10):

$$
\frac{\theta_{2}}{\theta_{1}}=a^{\prime}-b^{\prime} \theta_{1}
$$

onde $a^{\prime}$ e $b^{\prime}$ são constantes de valor aproximado

$$
a^{\prime} \approx 0,76(1)
$$

e

$$
b^{\prime}=\frac{0,76(1)-0,48(1)}{100(1)^{\circ}} \approx 0,0028(2) /^{\circ} .
$$

\section{Refração no dioptro ar-água}

Após termos investigado o dioptro ar-acrílico, vamos explorar os efeitos da água sobre a formação da imagem de um objeto. Primeiramente, colocamos o baptistir na vertical e preenchemos o seu recipiente semicilíndrico com água limpa e em quantidade suficiente para alcançar a sua borda. Em seguida, verificamos se a superfície do disco do baptistir está perpendicular à superfície da água. Esta superfície divide o disco em duas metades, de maneira que a metade $B G D$, fica inteiramente abaixo do nível da água. Assim, o diâmetro $A E G$ também está perpendicular a superfície da água, como ilustrado na Figura 10. E assim executamos os mesmos procedimentos realizados no dioptro ar água obtendo as seguintes medidas angulares conforme a Tabela 3 .

Com os dados obtidos e seguindo os mesmos passos já realizados chegamos aos seguintes valores para as constantes $a$ e $b$ de valor aproximado

$$
a \approx 0,85(1)
$$

e

$$
b=\frac{0,85(1)-0,57(1)}{100(1)^{\circ}} \approx 0,0028(2) /^{\circ} .
$$

Observamos mais uma vez que, para pequenas posições angulares das imagens podemos escrever a seguinte equação angular onde $a$ é o termo de proporcionalidade:

$$
\theta_{1} \approx a \theta_{2}
$$

\section{As características dos dioptros}

Uma análise das medidas para a posição angular do objeto, $\theta_{1}$, e da posição angular da sua imagem,

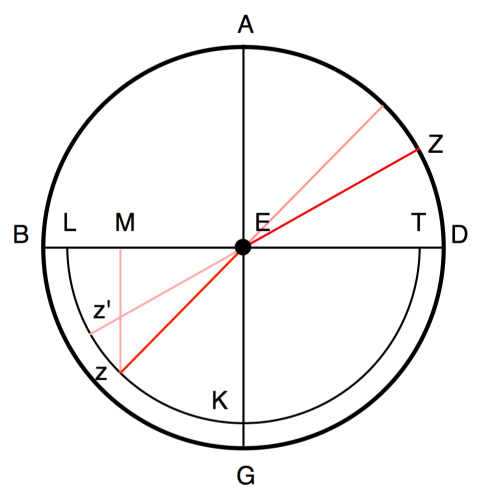

Figura 10: Baptistir e o dioptro ar-água.

Tabela 3: Medidas em graus para posição angular da imagem $\left(\theta_{2}\right)$ e do objeto $\left(\theta_{1}\right)$ para o dioptro ar-água.

\begin{tabular}{lcc}
\hline$\theta_{2}$ & $\theta_{1}$ & $\Delta \theta$ \\
\hline $10,0(2)$ & $9,0(2)$ & $1,0(4)$ \\
$20,0(2)$ & $16,0(2)$ & $4,0(4)$ \\
$30,0(2)$ & $23,0(2)$ & $7,0(4)$ \\
$40,0(2)$ & $29,5(2)$ & $10,5(4)$ \\
$50,0(2)$ & $36,0(2)$ & $14,0(4)$ \\
$60,0(2)$ & $41,0(2)$ & $19,0(4)$ \\
$70,0(2)$ & $44,0(2)$ & $25,5(4)$ \\
$80,0(2)$ & $49,0(2)$ & $31,0(4)$ \\
\hline
\end{tabular}

Revista Brasileira de Ensino de Física, vol. 39, nº 3, e3603, 2017 
$\theta_{2}$, para diferentes dioptros e quando o objeto é observado a partir do meio menos denso para o mais denso, mostraram que estas grandezas físicas obedecem a lei de Ptolomeu:

$$
\frac{\theta_{1}}{\theta_{2}}=a\left(1-\frac{\theta_{2}}{\theta_{0}}\right)
$$

onde $a$ e $\theta_{0}$ são constantes que dependem do dioptro considerado. Na Tabela 4 apresentamos um resumo das características dos dioptros analisados.

Uma análise da Tabela 4 mostra que o valor do parâmetro $a$ é menor para o dioptro ar-água do que o seu correspondente para o dioptro ar-acrílico. Entretanto, o dioptro ar-acrílico produz uma refração maior do que o dioptro ar-água. Podemos então definir um coeficiente $n_{P}=1 / a$ que represente este comportamento. Este coeficiente $n_{P}$ é denominado índice de refração do material.

Assim, podemos concluir que: (1) o encurvamento do raio visual não ocorre em qualquer líquido ou meios rarefeitos. Um certo grau de encurvamento ocorre somente no caso daqueles meios transparentes de características refratárias diferentes; (2) o raio visual se prolonga ao longo de um segmento de reta e é naturalmente encurvado somente na interface entre os dois meios transparentes de intensidades diferentes; (3) o encurvamento ocorre não somente na interface orientada de um meio menos denso para um mais denso (como no caso da reflexão) mas, também, na interface orientada de um meio mais denso para um menos denso; e (4) este encurvamento não ocorre em ângulos iguais, quando medidos em relação à perpendicular a interface entre o dois meios, mas eles apresentam uma relação quantitativa bem definida, descrita aproximadamente pela lei de Ptolomeu, dada pela equação (5).

\section{Considerações finais}

Destacamos neste trabalho o estudo da refração luminosa através de uma perspectiva empírica, sem a necessidade da apresentação de um modelo teórico prévio para análise dos dados observados e coletados. Na primeira etapa de nosso trabalho pudemos explorar geometricamente as posições das imagens e constatar visualmente os efeitos de refração, apenas com o uso da geometria plana elementar, constituindo-se num bom exercício didático para o entendimento qualitativo da refração entre meios.

$\mathrm{Na}$ segunda parte deste trabalho determinamos o grau de encurvamento tal como realizado por Ptolo- meu em seu tratado de óptica. Os resultados obtidos pelo nosso experimento mostram que os ângulos da posição da imagem, $\theta_{2}$, e a posição angular do objeto, $\theta_{1}$, se relacionam, em uma boa aproximação, por uma curva parabólica, para os dois dioptros investigados neste trabalho. Numa relação de causa e efeito, a lei de Ptolomeu (eq. (5)), o modelo matemático encontrado descreve o comportamento das posições de forma satisfatória, encontra a posição do objeto a partir da posição da imagem.

Outro fator importante está relacionado com o parâmetro $a$ da lei de Ptolomeu: vimos que o valor de $a$ varia de um dioptro para outro e, então, utilizamos o inverso deste parâmetro para definirmos o índice de refração $n$. Os valores encontrados para os índices de refração, como mostrado na Tabela 4, são bem razoáveis se comparados com os obtidos pela lei de Snell-Descartes para os mesmos valores 1,49(2) para o dioptro ar-vidro e 1,32(2) para ar-água.

Esse tipo de atividade é potencial para que os alunos possam desenvolver habilidades associadas à construção e à leitura de tabelas e gráficos, à construção e à representação de situações-problema, ao manuseio de equipamentos e de instrumentos de medida, à realização de medidas e à estimativa de incertezas, além de poder identificar as grandezas relevantes associadas ao problema e relacioná-las algebricamente, conforme sugerido pelos Parâmetros Curriculares Nacionais 10 .

Para finalizar, sabemos que atividades dessa natureza não são fáceis de serem desenvolvidas em aulas tradicionais e o sucesso dela depende de alguns fatores colaborativos que podem estar relacionados à formação prévia do estudante, à infra-estrutura da escola na disposição de equipamentos, aos recursos financeiros disponíveis ou ao tempo de dedicação. No entanto, não podemos esperar que esses aspectos se alterem para iniciar o trabalho em atividades dessa natureza com nossos alunos. Nesses casos, o planejamento pode fazer a diferença na aplicação de estratégias de ensino-aprendizagem em práticas laboratoriais nas escolas.

Nas palavras de Baker [11, "experimentar, em Ciências, é uma exploração, uma pesquisa no desco-

\section{Tabela 4}

\begin{tabular}{lccc}
\hline dióptro & $a$ & $b$ & $n_{P}=1 / a$ \\
\hline ar-acrílico & $0,74(1)$ & $0,0026(2)$ & $1,35(1)$ \\
ar-água & $0,85(1)$ & $0,0028(2)$ & $1,18(1)$ \\
\hline
\end{tabular}


nhecido." Deste modo, esperamos que este trabalho possa equipar os professores para esta exploração ao oferecer abordagens alternativas para o desenvolvimento de suas aulas e também os inspirar na produção de materiais dessa natureza, resgatando o papel da história da ciência e da experimentação científica na formação dos estudantes.

\section{Referências}

[1] R.P. Feynman, R.B. Leighton and M. Sands, The Feynman Lectures on Physics (Addison-Wesley, Reading, 1964), v. 1, p. 26-2.

[2] Epicuro et al., Epicuro, Lucrécio, Cícero, Sêneca e Marco Aurélio - Coleção Os Pensadores, organizado por J.A.M. Pessanha (Abril Cultural, São Paulo, 1985), $3^{\text {a }}$ ed, p. 184, tradução e Notas de A. da Silva, A. Cisneiros, G.D. Leoni e J. Bruna.

[3] G. Govi, L'Ottica di Claudio Tolomeo: da Eugenio Ammiraglio di Sicilia, Scrittore del Secolo XII. Ridotta in Latino Sovra la Traduzione Araba di un Testo Greco Imperfetto (Stamperia Reale Della Ditta GB Paravia, Turin, 1885), disponível em https://archive.org/ details/lotticadiclaudi00eugegoog, acesso em $13 / 2 / 2017$.

[4] A.L. Lejeune, Optique de Claude Ptolémée: Dans la Version Latine d'Après l'Arabe de l'Émir Eugène de Sicile (Presses Universitaires de Louvain, Louvain, 1956), Fascicule 8.

[5] M. Cohen and I. Drabkin, A Source Book in Greek Science (Harvard University Press, Harvard, 1958).

[6] A.M. Smith, Ptolemy's Theory of Visual Perception: An English Translation of the Optics with Introduction and Commentary (Transactions of the American Philosophical Society, Philadelphia, 1996).

[7] S. Wilk, Optics \& Photonics News 15, 14 (2004).

[8] M. Martinho, O Experimento de Ptolomeu: Uma Introdução ao Estudo da Refração Luminosa. Dissertação de Mestrado em Ensino de Física, Instituto de Física, Universidade Federal do Rio de Janeiro, 2013, disponível em http://www.if.ufrj.br/ pef/producao_academica/dissertacoes.html, acesso em 13/02/2017.

[9] M. Anderson, V. Katz e R. Wilson (eds) Sherlock Holmes in Babylon and Other Tales of Mathematical History (The Mathematical Association of America, Washington, 2004).

[10] Brasil, PCN+Ensino Médio: Orientações Educacionais Complementares aos Parâmetros Curriculares Nacionais; Ciências da Natureza, Matemática e suas Tecnologias (MEC/SEMTEC, Brasília, 2002).

[11] A.G. Baker, in: The Systematic Experiment: A Guide for Engineers and Industrial Scientists org. by J.C. Gibbings (Cambridge University Press, Cambridge, 1986). 